\title{
RPG: UMA ABORDAGEM EMPREGANDO SISTEMAS MULTIAGENTES
}

\author{
Mário Lúcio Mesquita Machado* \\ Diego Gomes de Souza** \\ João Artur de Souza ${ }^{* * *}$ \\ Gertrudes A. Dandolini* \\ Ricardo Azambuja Silveira***
}

\section{RESUMO}

Este artigo descreve as bases para a implementação de um jogo com finalidade pedagógica. Neste, o jogador controla um personagem, o qual tem que interagir com outros e com o ambiente, a fim de resolver problemas propostos pelo jogo. Cada personagem do jogo será moldado como um agente inteligente com tarefas bem definidas, de tal forma que o jogo se constitui em uma sociedade de agentes. Após as devidas considerações sobre RPG e agentes inteligentes, será feita uma discussão acerca da modelagem do jogo empregando agentes.

\section{PALAVRAS-CHAVE}

jogos, informática na educação, sistemas multiagentes, role playing games

\section{RPG: An Approach Using Multiagent Systems}

\begin{abstract}
This article describes the bases for a game implementation with pedagogical finality. In this game, the player controls a character who has to interact with the others and with the environment, in order to solve problems proposed by the game. Each character in the game will be mould like a intelligent agent with well-defined tasks, in a way that the game establishes itself in a agent society. After the proper considerations about RPG and intelligent agents, a discussion about the game modeling using agents will be made.
\end{abstract}

\section{KEYWORDS}

games, informatics on education, multi agents systems, role playing games

\section{INTRODUÇÃO}

Em se tratando de ensino, a ordem do dia pode ser reduzida a uma palavra: interação.Em um processo educativo, o aluno deve ser incentivado a participar, a buscar o conhecimento e a tirar conclusões baseado nos fatos que observa. Ou seja, o aluno tem que construir seus conhecimentos, em vez de adquiri-los prontos, como acontece geralmente no ensino tradicional.

Segundo (Barreto, 1997) Apud (Zuchi, 2000), "O computador é talvez a mais aperfeiçoada ferramenta que o ser humano já construiu para ampliar suas capacidades

\footnotetext{
* Graduando em Ciência da Computação pela UFPel, email: krazny@ufpel.edu.br, bolsista CNPq

** Graduando em Ciência da Computação pela UFPel, email: trunksgt@ ufpel.tche.br.

*** Professor Adjunto, Doutor em Engenharia de Produção, UFPel, Coordenador Pró-Tempore do Curso de

Licenciatura em Matemática a Distância, jartur@ufpel.tche.br , http://www.ufpel.edu.br/ifm/dmec.

***** Professora Adjunta, Doutora em Engenharia de Produção, UFPel, Coordenadora do Curso de Licenciatura em Matemática, gtude@ufpel.tche.br, http://www.ufpel.edu.br/ifm/dmec.

****** Professor Adjunto, Doutor em Ciência da Computação, UFPel, Responsável pelo TELEDUC, http://www.ufpel.edu.br/ifm/dmec
} 
intelectuais e cuja vocação é o armazenamento e manipulação de informações. Informações do mesmo tipo das que devem ser passadas de um ser humano a outro".

Nesse sentido, segundo (Andrade, 1997) "enfatiza-se que o computador deve ser utilizado não apenas como ferramenta pedagógica, ou como substituto do professor: a proposta é criar ambientes enriquecidos com a tecnologia, em que o professor seja o dinamizador das experiências e atividades pedagógicas.“

Muitas tentativas inovadoras têm sido introduzidas no sentido de aperfeiçoar as técnicas de ensino. Uma das preocupações constantes dos grupos de pesquisa. interessados na utilização do computador no processo de ensino/aprendizagem. consiste em encontrar formas mais adaptadas para explorar esta tecnologia na representação das estruturas cognitivas dos alunos. Os Sistemas Tutores Inteligentes (STI) são um exemplo dessas tentativas. Entretanto, da forma como eles estão sendo construídos, esses sistemas ainda não provêm a interatividade em um nível tão profundo quanto_o desejado.

Os jogos, por sua vez, têm um grande potencial para uso pedagógico, tanto pela forte atração que exercem, quanto pela necessidade de participação por parte do usuário, o qual se sente valorizado, na medida em que se torna parte ativa do processo.

assimilação funcional, num exercício das ações individuais já aprendidas, gerando, ainda, um sentimento de prazer pela ação lúdica em si e pelo domínio sobre as ações. Portanto, os jogos podem ter dupla função: consolidar os conhecimentos adquiridos e dar prazer ou equilíbrio emocional à criança (Dal Pizzo et al, 2001).

Dentre os diversos tipos de jogos existentes, serão analisados os assim chamados "jogos de interpretação de personagem" (RPG). Nesses, a atividade do jogador não é isolada, mas coordenada com a de outros jogadores ou personagens presentes no jogo. Além disso, a ação se desenrola em um ambiente, o que dá um contexto às atividades e às informações que são passadas ao jogador e aos conhecimentos que são construídos por este. Em tais jogos, os participantes são personagens de uma história que se desenrola, e suas ações vão modificá-la à medida que ela acontece. Os participantes vêem-se frente a situações que exigem criatividade, pesquisa e conhecimento da estrutura do mundo (cenários, objetos e personagens) no qual a história se desenrola, buscando superar situações de conflito, solucionar problemas, assimilando desta forma novos conhecimentos_(Andrade, 1997). Já existem iniciativas neste sentido, por exemplo, para o ensino de história (Dal Pizzo et al, 2001). Dada a sua flexibilidade, porém, o RPG pode ser adaptado para qualquer temática que se escolha, como por exemplo o trabalho desenvolvido por_(Zuchi, 2000) no campo da matemática.

$\mathrm{O}$ aspecto interação está fortemente vinculado à capacidade do sistema em se comunicar_e de demonstrar atividade. Assim sendo, os elementos do jogo, tanto o cenário como os personagens, devem ser concebidos de maneira a ter reações bem específicas e particulares às ações do jogador bem como apresentar um certo nível de "vontade própria". O jogador deve se sentir à vontade com o jogo.

Esse comportamento de interatividade vem naturalmente ao encontro dos conceitos de agente inteligente e de sociedade de agentes. Dada a natureza cooperante de determinados elementos desta estrutura, a modelagem, tanto do universo do jogo, quanto dos personagens pode ser feita empregando este paradigma.

Este artigo está dividido da seguinte maneira: na seção 2 será feita uma apresentação ao RPG e seus usos pedagógicos; na seção 3, os agentes inteligentes serão | explanados em maiores detalhes; na seção 4 será discutida a modelagem do jogo empregando agentes inteligentes e na seção 5 serão feitas as considerações finais. 


\section{MATERIAL E MÉTODOS}

\section{Role Playing Games ${ }^{1}$}

Deixando todas as definições de lado, os roleplaying games (RPG's) podem ser descritos como "jogos de interpretação com regras". Alguns talvez possam ter mais regras que outros. Alguns podem ser mais "interpretativos" do que outros. Mas a grande maioria tem em comum o contexto: "interpretação com regras".

De uma sessão de RPG participam o mestre e os jogadores. A função do mestre é apresentar ao grupo de jogadores uma história, uma aventura, que contenha enigmas, charadas, situações que exigirão escolhas ou decisões por parte dos jogadores. Estes, por sua vez, controlam personagens que viverão a aventura, discutindo entre si as escolhas que farão e as soluções que darão aos enigmas que surgirem.

A base do RPG é a criatividade. Ao preparar uma aventura, o mestre pode basear-se em aventuras já prontas ou criar novas, usando sua imaginação e pesquisas em livros, filmes, peças de teatro. O jogador cria seu personagem através de regras adequadas ao tipo de aventura a ser vivida e dirige suas ações durante o jogo. Esta flexibilidade traz possibilidades ilimitadas à história.

Parte do objetivo deste jogo é fazer com que o jogador enfrente a situação como seu personagem o faria. O RPG proporciona ao jogador representar o papel de um implacável samurai japonês, ou, um padre sensato, ou, um garoto de rua fazendo clandestinamente sua primeira viagem espacial ou qualquer outra personagem. Numa dada situação, o objetivo deste jogo é que cada um destes personagens reaja de maneira diferente (Jackson, 1994). É mais ou menos como se uma pessoa estivesse assistindo a um bom filme ou lendo uma revista em quadrinhos onde ela pudesse participar da história.

O RPG não é competitivo. A diversão não está em vencer ou derrotar os outros jogadores, mas em utilizar a inteligência e a imaginação para, em cooperação com os demais participantes, buscar alternativas que permitam encontrar as melhores respostas para as situações propostas pela aventura. É um exercício de diálogo, de decisão em grupo, de consenso.

O RPG desperta o interesse pela leitura e pesquisa. Após participar de algumas aventuras, a maioria dos jogadores sente o desejo de criar suas próprias histórias, ocupando o papel de mestre do jogo. Para isso deverá pesquisar sistemas de jogos, roteiros e informações que complementem sua história. É comum que os mestres estejam às voltas com livros de história, geografia ou ficção, buscando dados para suas próximas aventuras. Mesmo o jogador, nas aventuras pedagógicas, pode ser incentivado a fazer pesquisas para municiar-se de informações e aumentar suas chances de contribuir com o grupo na próxima aventura.

No RPG, o jogador não é um mero espectador, mas um participante ativo, que como um ator, representa um papel e, como um roteirista, escolhe caminhos e toma decisões nem sempre previstas pelo mestre, contribuindo na recriação da aventura.

Tudo isso torna o RPG muito mais que um jogo. No prefácio de GURPS (um dos mais vendidos sistemas de RPG - Devir Livraria), o editor afirma: "Os participantes redescobrem a arte ancestral de criar, ouvir e contar histórias".

Mais recentemente, educadores têm percebido o potencial que o RPG tem como instrumento pedagógico. Talvez a maior dificuldade que o professor enfrenta é

\footnotetext{
${ }^{1}$ Os dados apresentados até aqui sobre RPG nesta seção são oriundos de (Marcatto, 2003) com pouca ou nenhuma modificação. 
estimular o interesse do aluno por conteúdos que não pareçam ter aplicação imediata em sua vida. $\mathrm{O}$ aluno, então, estuda por estudar, para atender a uma obrigação, para ser aprovado ao final do ano letivo e não para desenvolver seus conhecimentos e capacidades que permitirão maior liberdade de escolha e satisfação em sua vida.

Muitas das tentativas de auxiliar na aprendizagem escolar estão voltadas ao universo lúdico ou da fantasia. O RPG pedagógico é uma ferramenta para a criação de simulações práticas, vivenciais em sala de aula, incentivando a criatividade, a participação, a leitura e a pesquisa. Ele é adaptável a qualquer matéria ou conteúdos didáticos, para crianças, adolescentes ou adultos (Zuchi, 2000).

Se for trazido para dentro da sala de aula como uma outra matéria, ou como atividade obrigatória, ou mesmo sob outras formas de indução (através de ponto extra na média ou coisas do gênero), ele perde o seu maior trunfo, que é a espontaneidade e a sensação que o jogador tem de ter um domínio, ainda que parcial, no desenvolvimento da história. O que ocorre numa sessão de RPG, de certa forma, é parte de sua criação. A partir daí, o jogador/aluno é levado a querer conhecer mais profundamente os elementos que compõem esta história, esta ambientação. Tal conhecimento se torna necessário para um melhor desenvolvimento de seu personagem e, conseqüentemente, da história criada coletivamente (Andrade, 1997).

\section{Agentes InTeligentes e Sistemas MultiagenteS}

\section{Agentes}

De acordo com (Wooldridge, 1998), "Um agente é um sistema de computador que está situado em algum ambiente e que é capaz de executar ações autônomas de forma flexível neste ambiente, a fim de satisfazer seus objetivos de projeto". Três conceitos estão incluídos nesta definição:

1. Ambiente: significa que o agente recebe informações do meio e efetua alterações neste de alguma forma.

2. Autonomia: "significa que o sistema é capaz de atuar sem intervenção humana e tem controle sobre suas ações e seu próprio estado interno" (Meneses, 2001).

3. Flexibilidade: Para (Jennings et al, 1998), flexibilidade significa que o agente é

- Reativo: os agentes devem detectar as alterações no ambiente e atuar em respostas a estas alterações;

Pró-ativo: o agente deve tomar iniciativas no sentido de cumprir as suas metas, não apenas agindo em resposta às situações do ambiente;

- Social: o agente deve, quando necessário, atuar em conjunto com outros agentes ou humanos no sentido de completar suas tarefas ou ajudar outros em suas atividades.

Os ambientes podem ser classificados segundo (Russel et al, 1995) sob os seguintes aspectos: Acessível X Inacessível, Determinístico X Não-determinístico, Episódico X Não-episódico, Estático X Dinâmico e Discreto X Contínuo. A análise para o nosso caso específico será feita posteriormente.

Pode-se notar que, durante o desenrolar das ações, tanto o jogador quanto os outros agentes, estarão cientes das mudanças no espaço do ambiente ao seu redor, o que caracteriza a acessibilidade do mesmo. Devido ao fato dos agentes terem um repertório 
de possíveis ações, e que tais ações, estão vinculadas às crenças do agente naquele momento, nem sempre uma dada ação do personagem será disparada pelo mesmo evento, o que evidencia o não-determinismo do ambiente. Ele é discreto devido ao número finito (ainda que grande) de estados possíveis dentro do jogo. Apesar de o desenvolvimento do jogo ser dividido em etapas, de modo a facilitar a organização, as decisões tomadas em uma etapa influenciam o curso dos acontecimentos das etapas subseqüentes. Isto caracteriza o ambiente como não episódico. Como o ambiente não muda suas características durante as decisões do jogador e dos outros agentes, diz-se que ele é estático.

Geralmente, os agentes têm um repertório de ações que ele pode executar para modificar o ambiente.. O problema chave é decidir qual ação executar para alcançar seus objetivos de projeto, dadas determinadas pré-condições. No caso de um agente puramente reativo, as suas ações são determinadas unicamente pelo estado atual do ambiente. Outro tipo de agente, os com estado interno, baseiam-se em seu próprio estado interno, além das impressões do ambiente para a sua tomada de decisões.

Todo agente é construído com base em uma determinada arquitetura, a qual descreve como um agente é constituído internamente. Segundo (Jennings et al, 1998) uma arquitetura é: "um mapa interno de um agente - suas estruturas de dados, as operações que podem ser executadas e o fluxo de controle delas".

\section{Arquiteturas Belief-Desire-Intention (BDI)}

Esta arquitetura baseia-se na noção de atitudes mentais de Crença (Belief), desejo (Desire) e intenção (Intention) representando, respectivamente, aos estados de informação, motivação e de deliberação do agente. Estes estados são usados para representar aquilo que o agente sabe (ou acredita que sabe), suas metas e seus planos. Dessa forma, pode-se definir um comportamento para o agente.

Conforme (Meneses, 2001): "Os componentes básicos da arquitetura BDI são estruturas de dados representado as crenças, desejos e intenções do agente, e funções que representam suas deliberações (decidindo que intenções deve ter, isto é, o que fazer) e raciocínio direcionado para objetivos (decidindo como fazer). As intenções têm um papel central no modelo BDI: elas dão estabilidade para o processo de tomada de decisão, e atua focando o processo de raciocínio prático do agente.“

Tais características tornam esta arquitetura a escolha ideal para a tarefa de modelagem dos personagens.

\section{Sistemas Multiagentes}

De acordo com (Meneses, 2001): "Sistemas Multiagentes são sistemas constituídos de dois ou mais agentes, em um ambiente, que interagem para alcançarem alguns objetivos. Esses objetivos podem ser comuns a todos os agentes ou não. $\mathrm{O}$ ambiente pode ser aberto ou fechado, pode ter número fixo ou variável de agentes, os agentes podem ser heterogêneos ou homogêneos, colaborar ou competir, etc." Pode-se observar que, para o desempenho de suas ações, alguns agentes do jogo, como será visto adiante, deverão comunicar-se para manter suas crenças coerentes, e para cooperarem em tarefas nas quais as suas informações são incompletas quando tomadas isoladamente para cada agente, mas suficientes se combinadas. Tal enfoque caracteriza o jogo proposto (RPG) como um clássico exemplo de sistema multiagentes.

\section{MODELANDO O JOGO E OS AGENTES}


O jogo a ser criado tem a incumbência de fazer com que o jogador construa uma dada classe de conhecimentos (implícita ou explicitamente) enquanto jogue. Ainda mais, que esse jogo seja atrativo a tal ponto que o jogador se sinta motivado a jogá-lo tal como outros jogos de natureza recreativa, e não na qualidade explícita de "lição" ou "obrigação". Entretanto, essa dificuldade pode ser reduzida a níveis tratáveis se uma abordagem eficiente for efetuada em seu projeto.

A proposta é mostrar como as estruturas do jogo podem ser elaboradas empregando-se uma abordagem orientada a agentes. Tanto a história como as suas caracterizações, que são tão importantes para o sucesso do jogo, quanto a parte "inteligente" para a contextualização pedagógica, dependem majoritariamente da sensibilidade em vez da técnica.

O primeiro passo nessa tarefa é a elaboração de uma história que contemple os objetivos subjacentes ao jogo. Cenários, personagens e objetos devem ser cuidadosamente elaborados e suas relações entre si e com o jogador devem ser estabelecidas. Nesta fase, é feito, também, o planejamento didático-pedagógico do jogo, ou seja, dos pontos onde o conteúdo será apresentado, por quais elementos ele será apresentado e dos desafios relacionados a eles a serem propostos ao jogador.

\section{Personagens}

Depois de concluída esta fase, é preciso definir os agentes que constituirão o jogo, na forma de personagens. Da história previamente construída se extrai o conjunto de comportamentos de cada personagem/agente. Podem-se agrupar os personagens em quatro grandes grupos.

1. Auxiliadores voluntários - são acionados pelo sistema, de forma a prestar alguma forma de ajuda (seja conteúdo, seja um aviso em caso de uma eventual ação desastrosa por parte do jogador) ao jogador.

2. Informativos - possuem informações importantes ou úteis ao jogador, porém, devem ser consultados por este. Eles podem solicitar algo ou nada em troca da informação.

3. Sentinelas - sua função é barrar a passagem do jogador a determinadas áreas do cenário do jogo, as quais só podem ser alcançadas após sucesso(s) em desafios propostos pelo jogo ou após o personagem ter acumulado um número predeterminado de pontos em uma dada habilidade ou atributo.

4. Figurantes puros - são personagens cuja função é apenas a de contextualização das situações. Assim, em uma praia, por exemplo, um surfista seria um figurante.

$\mathrm{Na}$ qualidade de entes que devem manifestar comportamentos e reações de perfil tão humano quanto o possível, devem ser empregados agentes animados para a simulação de personagens. Para estes agentes, além da especificação de seus estados mentais, os quais definem seu comportamento e suas metas, existe uma especificação de suas ações físicas (movimentos, gestos).

Dentro de um sistema multiagente, estão previstas formas para que os agentes troquem informações entre si. Uma linguagem específica, chamada linguagem de comunicação de agentes, é empregada. Esta define as regras que norteiam a comunicação e permitem a definição da semântica dos dados trocados. Neste jogo em específico três tipos de comunicação estão previstos: comunicação direta entre dois personagens, via linguagem de comunicação de agentes, comunicação entre o personagem e o ambiente via linguagem de comunicação de agentes, e comunicação entre os personagens via alterações no ambiente. Este último pode ser considerado como um mecanismo de comunicação de um nível mais alto de abstração. 


\section{Cenário}

As classes de personagens supracitadas são genéricas. Os caracteres que farão diferentes entre si os personagens de uma mesma classe serão dados pelo cenário. Dentro do contexto de agentes inteligentes, o cenário será o ambiente para estes agentes e, tanto eles como o jogador, extrairão suas percepções e efetuarão suas ações no(s) cenário(s) criado(s) para a história. As ações do jogador no cenário terão um impacto muito importante, visto que podem determinar a cooperação ou a hostilidade dos personagens, ajudá-lo a descobrir pistas ou a cair em armadilhas.

Por trás do cenário, está o agente gerenciador de cenário, cuja função é monitorar as ações do jogador e, em ocasiões oportunas, acionar auxiliadores ou sentinelas, informar aos personagens/agentes pertinentes sobre alterações ambientais efetuadas pelo jogador ou outros personagens. Essas ações são implícitas. Utilizam-se alterações nas condições do ambiente para representar passagem de tempo, mudanças climáticas e outras circunstâncias ditadas pela história do jogo. Como foi ressaltado anteriormente, o cenário também serve como meio de comunicação indireto para diferentes personagens, que, podem deixar mensagens para outros através de alterações neste. A interação em background entre o cenário e os agentes é dada via mensagens utilizando uma linguagem de comunicação de agentes.

Do ponto de vista pedagógico, o cenário dará todo o suporte contextual para os conteúdos abordados pelo jogo. Observa-se que, certos ambientes e certos épocas do tempo são mais adequadas que outras na proposição de determinados conteúdos. $\mathrm{O}$ Egito Antigo seria um lugar desaconselhável para um jogo destinado a ensinar Eletrônica, dada a dificuldade de contextualizar tais conceitos em tal ambiente. Entretanto, isso não é uma regra, mas sim uma questão de simplicidade de elaboração. Nada impede que um elaborador criativo invente e implemente uma história nesses moldes.

\section{DISCUSSÕES E RESULTADOS}

O atual estágio de avanço das tecnologias ligadas à elaboração de jogos, aliado às técnicas de inteligência artificial, permite a confecção de jogos cada vez mais atraentes, criativos e ricos em recursos. $\mathrm{O}$ uso de tais recursos como ferramenta pedagógica deve ser expandido e novas iniciativas devem ser estabelecidas neste sentido. Este projeto contempla apenas uma destas iniciativas. Contudo, muito ainda há por pesquisar e o modelo apresentado ainda está no início de seu desenvolvimento.

O objetivo deste trabalho está relacionado com o processo ensino-aprendizagem e a busca por alternativas que facilitem esta questão. A adequada aplicação do computador pode extrair muito mais do educando em termos de aproveitamento e criação de subsídios necessários à compreensão dos conceitos matemáticos, por exemplo.

Uma interface utilizando a ferramenta RPG MAKER está sendo utilizada para a realização de testes. Uma história envolvendo conteúdos de frações e raciocínio lógico esta sendo implementada (Figura 1). 


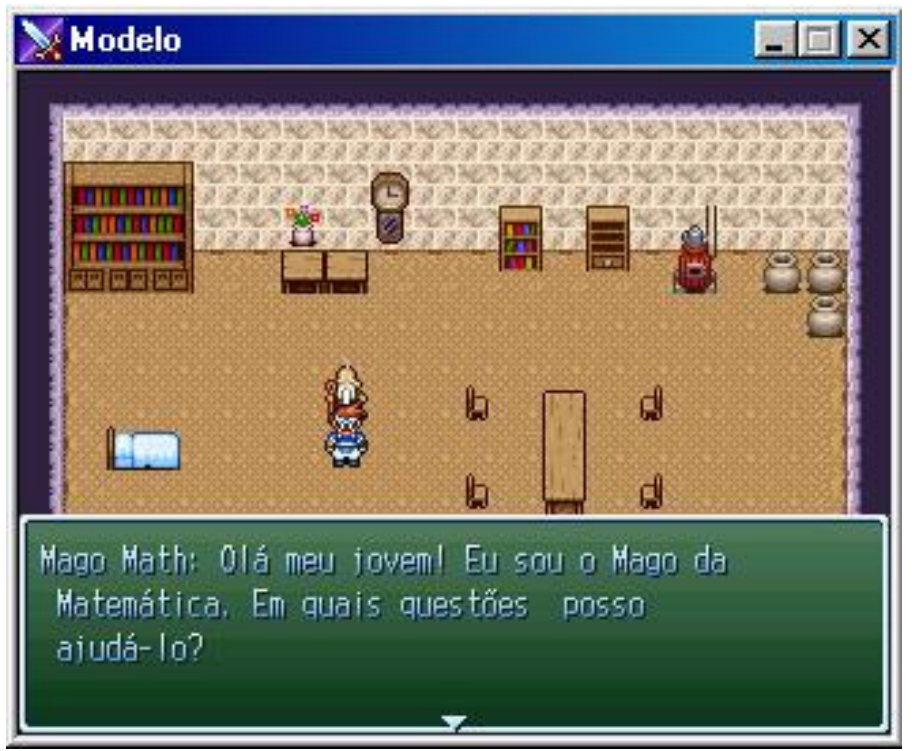

Figura 1 - Mago da Matemática

\section{CONCLUSÕES}

O uso de técnicas de RPG proporciona uma interface lúdica, que desperta o interesse e a curiosidade do usuário, estimulando-o e desafiando-o. A utilização do computador torna-se adequada quando ele perde sua posição de passividade no quadro pedagógico, sendo que isso é conseguido na medida em que o computador propõe questões, sugerem alternativas, oferece ajuda e traça um perfil do aluno para que esse possa se aperfeiçoar.

\section{Referências Bibliográficas}

ANDRADE, F. RPG e Educação - Possibilidades de uso do RPG. 1997. Disponível por WWW em http://www.historias.interativas.nom.br/educ/rpgtese.htm acessada em 14/07/2003.

BARRETO, J. M. (1997), Inteligência Artificial no Limiar do Século XXI Florianópolis:ppp Edições, 1997. 291 p.

DAL PIZZO C., ZANATTA A. O RPG como técnica na construção de software educacional: A Revolução Farroupilha, Simpósio Brasileiro de Informática na Educação 2001, disponível na WWW em <www.inf.ufes.br/ sbie2001/figuras/ artigos/a012/a012.htm>, acesso em 12/06/2003

FARIA, A. R. de. O desenvolvimento da criança e do adolescente segundo Piaget. Ed. Ática, 30 edição, 1995.

JACKSON, S. GURPS: Generic Universal Roleplaying System: Modulo Básico; tradução de Douglas Quinta Reis; revisão Cynthia Monegaglia Fink. 2a Edição. São Paulo: Devir, 1994. 
JENNINGS, N., SYCARA, K., WOOLDRIDGE M.. A Roadmap of Agent Research and Development, 1998.

MARCATTO, A. RPG Pedagógico - O que é?, artigo retirado de SpellBrasil Roleplaying Games, disponível da WWW em <www.rpg.com.br>, acesso em $24 / 03 / 2003$

MENESES, E., SILVA F. Integração de Agentes de Informação, Jornada de Atualização em Inteligência Artificial, 2001, disponível na WWW em <www.ime.usp.br/ eudenia/jaia/texto/> acesso em 20/06/2003

RUSSELL S., NORVIG. P. Artificial Intelligence: A Modern Approach, PrenticeHall, 1995.

WOOLDRIDGE. M. Multiagent Systems. A Modern Approach to Distributed Artificial Intelligence. MIT Press, 1999.

ZUCHI, I. O Desenvolvimento de um Protótipo de Sistema Especialista Baseado em Técnicas de RPG para o Ensino de Matemática. Florianópolis: Dissertação (Mestrado em Engenharia de Produção). Programa de Pós-Graduação em Engenharia de Produção e Sistemas, Universidade Federal de Santa Catarina, 2000. 